\title{
NOTAS SOBRE LA EXPERIENCIA DEL VALOR
}

o.oo. Preliminares

o.10. A fin de tratar correctamente la problemática axiológica es necesario tener una suficiente familiaridad con los hechos de la experiencia valorativa y someter a un detenido análisis los principales conceptos relativos a dicha experiencia. Cuando no se toma esta precaución y se aborda directamente el estudio del valor o de lo valioso - sea esto lo que fuere-, frecuentemente la reflexión naufraga en el error y en una especulación huérfana de base y soporte. Con independencia de cualquier teoría sobre la naturaleza y el fundamento del valor, como trámite previo a la formulación y discusión de las tesis axiológicas interpretativas, precisa por tanto observar y describir la vivencia de lo valioso y definir los conceptos implicados en el lenguaje del valor.

o.20. Como una primera aproximación al tema, nuestro trabajo se desenvuelve a la vez en el plano de la experiencia de la vida valorativä y en el del examen del lenguaje y las significaciones que él comporta. Utiliza así la observación y la descripción de casos y el análisis de las posibilidades lógicas de los conceptos. Este doble enfoque nos parece indispensable para cumplir las metas de una reflexión propiamente filosófica sobre el valor, diferente de los estudios que se sitúan en el plano psicológico, sociológico, antropológico, y, en general, empírico positivo. No queremos, pues, divorciar la filosofía de la experiencia, pero tampoco justificar una invasión por el axiólogo de los terrenos propios del psicólogo $u$ otro investigador en el campo de las ciencias humanas, ni confundir filosofía y descriptiva del lenguaje. Tampoco sujetar los planteos filosóficos a la metodología de in. vestigaciones de esencia diversa. Nuestro propósito es otro y debe quedar claramente señalado: se trata de utilizar las conclusiones psicológicas y científico-sociales y los aportes lingüísticos como elementos auxiliares de control, como recurso iluminador y como fermento del trabajo axiológico.

o.go. La referencia a la experiencia, y su complementación o, en otros casos, su prolongación por el análisis de las significaciones, permiten definir el carácter de nuestro trabajo como fenomenológico. Fenomenológico es también en cuanto pretende moverse -y creemos que lo consigue- en un ámbito previo a las interpretaciones y las cuestiones de fundamentación. Debe, por tanto, tenerse presente todo el tiempo que las expresiones del lenguaje ordinario o filosófico que hemos de emplear a lo largo del texto para comunicar los diversos conceptos que formulamos, no implican para nosotros una decisión sobre la naturaleza del valor y otros temas afines, o, dicho de 
modo diverso, sobre el sentido de palabras como "valor", "bueno", "malo" y otras por el estilo. Habrá, por cierto, una inevitable carga subconsciente de prejuicios, creencias, ideas recibidas y otros contenidos semejantes en el modo en que empleamos el lenguaje en este trabajo y en el modo en que lo en. tiendan quienes lo lean. Pero esto, aparte de ser inevitable, no debe confundirse con tesis aceptadas y formuladas. Temáticamente, aquí no se supone aceptada ninguna teoría sobre el valor. Por tanto; cuando hayamos de decir, v. gr., que hay realización de valores o que el sujeto aprecia positiva o negativamente las cosas valiosas y juzga a las personas buenas o malas, los instrumentos útiles en mayor o menor grado, etc., no supondremos -y el lector no debe tampoco suponer por su cuenta- más de lo que queda expresado en las definiciones que hayamos de formular, y debe por ende considerársenos teóricamente indiferentes a cualquier interpretación que se dé del sentido de los términos implicados en nuestras afirmaciones, siempre que esto no afecte o contradiga el contenido de los enunciados analíticos y descriptivos que hemos de formular.

\section{0o. La conciencia valorativa}

1.10. El nivel fáctico en que, sin correr demasiados riesgos, puede trabajar la investigación axiológica es el de la experiencia humana consciente o conducta individual y social ordinaria. Existen suficientes datos y amplias posibilidades de observación y control de comportamientos de este tipo. Por lo mismo, una investigación que se apoya en ellos puede conducir a resultados teóricamente bien fundados y eventualmente muy fecundos para la axiología. El hecho de la comunicación humana, pese a todas las limitaciones y dudas que puedan señalarse, es buena prueba de que aquí pisamos un terreno bastante firme. En cambio, no existen datos bastantes y seguros, ni es posible anticipar que existan en el futuro, sobre otros tipos de experiencias, como pueden ser la animal o la humana extraconsciente. Sin negar pues, a priori, la existencia de tales géneros de conducta estimativa, conviene limitar la descripción y el análisis a los fenómenos de orden estimativo vividos por el hombre en estado consciente.

1.21. Dentro de este vasto horizonte empírico, que comprende vivencias y conductas de todos los tipos, banales y raras, simples y complejas, permanentes o episódicas, pueden por lo menos distinguirse dos formas bien definidas de conciencia: la valorativa y la constativa. Aquí nos interesa la primera, pero es conveniente detenerse brevemente en la segunda para mejor determinar, por contraste con ella, los caracteres de la conciencia del valor. Con este mismo objeto, no insistiremos en los rasgos que ambas poseen en común - que no deben por cierto ser olvidados- y enfatizaremos las diferencias, sin perjuicio de reconocer que éstas son en mucho distinciones ana- 
líticas introducidas con propósito cognoscitivo en la continuidad concreta de la vida.

1.22. Para comenzar, se comprueba fácilmente la amplitud y variedad de casos que cubre el primer tipo de conciencia o experiencia consciente. Ella comprende, en efecto, actos del tipo del percibir, observar, recordar, ensoñar, fantasear, pensar, probar, explicar, argumentar, describir, descubrir, confundir, diferenciar, definir, reconsiderar, especular, aclarar, declarar, etc., para mencionar, en una enumeración desordenada, sólo algunos ejemplos posibles.

Aquí, lo constante, como rasgo fenomenológicamente describible, es un darse cuenta y un dar cuenta de lo que ocurre tal como ocurre, o de lo que es, tal como es, o de lo que se presenta o aparece, tal como se presenta o aparece, comprendiendo en este darse cuenta y dar cuenta, intenciones objetivas de todo tipo: relaciones, estados situaciones, propiedades, actos, usos y otros fenómenos pertinentes. Para nuestro objeto no resulta importante la diferencia entre lo que ocurre, lo que es y lo que aparece, si la hubiere, pero mencionamos esos casos para cubrir los varios aspectos posibles del género de conciencia que nos interesa señalar. Por significar bien la palabra "constatar" todos estos posibles aspectos, hablamos de experiencia o conciencia constativa.

1.31. Por su parte, la conciencia o experiencia estimativa se ofrece también con una gran variedad y amplitud de formas. Algunas son las siguientes: valorizar, apreciar, estimar, preferir, elegir, recomendar, exhortar, aprobar, censurar, reprobar, prevenir, despreciar, encomiar, etc. Todos estos casos de actos y comportamientos presentan diversos rasgos comunes, algunos compartidos por las formas de la conciencia constativa y otros exclusivos. Estos últimos se agrupan alrededor de lo que vamos a llamar el compromiso de la conciencia. Frente a la neutralidad de la conciencia constativa, en la valorativa el sujeto está siempre a favor o en contra del objeto, se inclina hacia él o lo rechaza. Esta respuesta afectiva y activa de la conciencia hace que en la valoración el sujeto esté comprometido, tenga siempre un partido tomado, aunque se mantenga en el mero nivel de los actos sin correlato exterior. Con este compromiso están vinculadas la polaridad de la conciencia y las funciones de graduación y jerarquización. Ninguna de ellas, en efecto, es comprensible sin el estar a favor o en contra. En caso contrario, corren el riesgo de ser confundidas con otras formas vivenciales propias de la conciencia constativa. Asi, por ejemplo, graduar el valor de varios objetos es, pese a posibles analogias, acto diferente en esencia de distinguir gamas de propiedades, $v$. gr., colores, estribando justamente la diferencia en el estar a favor o en contra, en el mayor o menor compromiso del sujeto.

1.32. Es importante señalar aquí que en toda experiencia valorativa intervienen también como factores esenciales un sujeto y un término objetivo, 
ligados ambos a través de uno o múltiples actos. Esta afirmación no es un truismo, toda vez que se ha negado la referencia objetiva de los enunciados de valor y se ha identificado, con no poca frecuencia, el valor y la vivencia. Por lo demás, el objeto o instancia objetiva puede ser de los más diversos géneros, como en el caso de la conciencia constativa. En lo que sigue consideraremos la función de cada uno de estos momentos básicos al describir las principales formas de la experiencia valorativa. Adoptaremos una actitud fenomenológica, entendiendo por este término, como hemos dicho, un enfoque descriptivo previo a toda interpretación y teoría e independiente, por tanto, de las tesis con que se busca resolver las cuestiones relativas a la naturaleza y el fundamento del valor. En aquellos casos en que esta problemática (cuya importancia no ponemos en duda, pues la consideramoś meta propia de la indagación axiológica) se encuentra complicada en la temática de la valoración, trataremos cuando menos de mantenernos dentro de los límites de un enfoque predominantemente descriptivo.

Entre las varias formas de la experiencia valorativa que hemos mencionado antes y otras que cabría señalar, concentraremos nuestra atención en los siguientes tipos generales de vivencia: la atribución de valor, la realización del valor, la preferencia y la elección. Las estudiaremos primero de modo genérico, y luego reexaminaremos algunos de sus principales rasgos a la luz de la distinción de dos niveles de la vida valorativa.

\subsection{La atribución de valor}

2.01. Conviene considerar, como enfoque previo a la descripción de la atribución dẹ valor, la cuestión de su prioridad como acto simple, o sea, si ella se da aislada y en forma pura. La experiencia más extendida parece indicar lo contrario. El calificar a un objeto de bueno o malo es normalmente resultado de preferencias y elecciones, de contrastes y analogías percibidos entre diversos objetos en situaciones y momentos diferentes. Quizá nadie puede decir, de hecho, que un objeto tiene determinado valor con abstracción del resto de la realidad. Sin embargo, esto no impide que analíticamente, no como una afirmación fáctica, se pueda determinar y describir un tipo simple y primario de vivencia, que consiste en la atribución de valor a una instancia cualquiera. A este tipo hemos de dirigir nuestra atención en lo que sigue.

2.11. El primer rasgo a notar en los actos de atribución de valor es la referencia a un objeto cualquiera, sea éste presente, pasado o extraño al tiempo, real o imaginario. El objeto puede ser tomado como término de la conciencia de un modo simple y directo o bajo determinadas condiciones.

Esto no introduce ningún cambio esencial en el carácter de la vivencia, tal como aquí la consideramos. Así, es igualmente una atribución de valor: 
el considerar excelente a un auto que estamos contemplando, que el considerarlo del mismo modo viéndolo funcionar, o el juzgarlo excelente a condición de que se modifiquen ciertas partes de él. La igualdad esencial se mantiene aquí en la medida en que en todos los actos hay un término objetivo y una calificación que el sujeto atribuye, sin necesidad de que él opere sobre el objeto.

2.12. En segundo lugar, notemos que basta que haya un solo objeto para que se dé una atribución de valor. No es necesaria, pues, una pluralidad de correlatos intencionales. Cuando ésta se da en la atribución, ocurre que el objeto es tomado como un término colectivo o una clase. Juan es bueno o Los alumnos de este año son buenos son enunciados que corresponden del mismo modo a una atribución de valor. Dicho de otro modo, basta que se dé un objeto considerado por la conciencia para que haya atribución de valor.

2.13. Se requiere, además, que dicho objeto sea considerado en su modo y sus caracteres propios, esenciales o adquiridos. No hay atribución de valor con una referencia indeterminada a un objeto cualquiera o con una simple mención de caracteres desconocidos o no poseídos por un objeto (salvo cuando se le atribuye valor potencial o valor perdido). Es preciso que el sujeto valorante tome nota del objeto tal como es y con el mayor pormenor de rasgos y circunstancias.

2.21. Como base de la atribución de valor se reconoce así una conciencia constativa que da cuenta de los caracteres, estado y situación de las cosas juzgadas. Éste es el primer elemento cognoscitivo - a la vez perceptivo, imaginativo, mnemónico y conceptual - que hay que mencionar al describir la vivencia que nos ocupa.

2.221. Otro es el juicio en que se formula la atribución de valor o calificación valorativa, el cual tiene generalmente la forma de un enunciado predicativo, como, v.gr., esta película es buena o Los alumnos de esa escuela son malos. Muchas veces este juicio es resultado o forma parte de una cadena discursiva, que opera con las significaciones relativas a los objetos, así como a sus propiedades, relaciones, estados, etc.

2.222. Al comportar un elemento judicativo (tanto constativo como estimativo), la atribución de valor, en cuanto se formula en enunciados, tiene que ver con la verdad y la falsedad, así como con la mentira, el encubrimiento y la simulación. Aparte de la posibilidad de afirmar o negar la existencia de propiedades o relaciones en los objetos valorados, cabe afirmar o negar bondad o maldad, así como otros tipos y grados de valor, ${ }^{1}$ lo cual significa que tales aseveraciones pueden ser calificadas de verdaderas o falsas, aunque

1 Lo que aqui decimos debe ser tomado en un sentido tal que excluya toda tesis sobre ia naturaleza del valor, esto es, como una comprobación previa a cualquier teoría interpretativa o compatible con varias de ellas. 
no sean constativas. Pero, por otra parte, es posible también engañar a otros acerca del valor reconocido a un objeto, sin que la atribución de valor sea afectada, lo mismo que encubrir, o disimular la atribución aceptada. Hay, pues, una mentira valorativa, como hay un encubrimiento y una simulación relativas a la apreciación. Importa subrayar lo siguiente a este respecto: si negamos la posibilidad de determinar como verdadero o falso un enunciado valorativo, la atribución de valor, uno de cuyos momentos fundamentales es el juicio, resulta afectada. Por otra parte, cabe aceptar la existencia de engaño, encubrimiento, simulación y otras vivencias afines, relativas a la valoración, sin que se desnaturalice o afecte la atribución de valor.

2.23. Nótese que hablamos de juicios, raciocinios y conceptos de dos clases por lo menos: los correspondientes a las simples comprobaciones del mundo objetivo y los que tienen que ver con lo propiamente valioso. Por ejemplo, en una vivencia estimativa con respecto a un cuadro, se pondrán en juego, de una parte, factores conceptuales, judicativos y discursivos del género de la enunciación este trazo es delgado, o la derivación si es un cuadro con tal tratamiento de la perspectiva, entonces no es anterior al siglo $\mathrm{x}$, $\mathrm{o}$ referentes a la forma, el color, etc., y, de otra parte, enunciaciones del género de este trazo es delicado, o conceptuaciones y derivaciones referentes a la calidad estética o al valor económico de la pintura. Ambas clases de factores intelectuales se vinculan, por cierto, estrechamente entre sí, en un modo que debe ser precisado. Considerémoslo brevemente a continuación.

2.241. Con respecto a los conceptos importa notar, en primer lugar, que, expresa o tácitamente, en toda valoración opera un concepto de la cosa buena, de un género variable en cada caso. ${ }^{2}$ Así, cuando se juzga estimativamente una mesa de billar determinada, se afirmará que es buena o mala en función de un concepto de la mesa de billar buena o de lo bueno en mesas de billar. Este concepto incluye una constelación de propiedades o características que son las que hacen buena a la cosa del género en cuestión. ${ }^{3}$ Ahora bien, las características incluidas en el concepto de la cosa buena son propiedades descriptivas ordinarias que podrian ser consignadas en una representación neutral del objeto.

Por donde se ve que el concepto valorativo de la cosa buena se apoya en la materia propia de los conceptos constativos ordinarios. Sin embargo, investigaciones axiológicas recientes ${ }^{4}$ permiten afirmar que el concepto esti-

2 Con la diferencia que introduciremos en la sexta parte de este trabajo será posible distinguir entre los conceptos recibidos y los conceptos creados por el sujeto. Cf. parágrafo 6.12 y siguientes.

3 Good-making properties, para emplear la expresión inglesa introducida por C. E. Broad.

4 Por ejemplo, R. Hare ha mostrado que el sentido evaluativo de "bueno" es previo al descriptivo y que éste cambia con las variaciones que se producen en aquél. Cf. The Language of Morals, Oxford University Press, 1962. En la misma dirección se orienta, en el fondo, la tesis de Max Scheler sobre los bienes, concebidos como unidades de cualidades fundadas en el valor. Cf. Der Formalismus..., primera parte, sec. primera, cap. Irr. 
mativo es condición de la constitución de los conceptos constativos correspondientes o, si se quiere, para no complicar la exposición, de la selección de las notas descriptivas que sirven para definir la cosa valorada.

2.242. Intimamente ligada con la función conceptuadora de la experiencia valorativa está la conformación de un patrón de valoración. En efecto, al concepto de la cosa buena (según el género) corresponde un patrón o modelo valorativo que señala cuáles son los caracteres que un objeto debe reunir para ser considerado bueno. Dicho de otro modo, el concepto de la cosa buena, considerado desde el punto de vista de las prescripciones valorativas y de la determinación de criterios de valoración, se traduce en una norma que fija un patrón o modelo evaluativo. No interesa precisar por el momento si tal patrón es variable o fijo, y si el sujeto lo recibe totalmente conformado o lo forja o compone por su cuenta, así como hasta qué punto es producto social o individual. 5 Aquí sólo interesa señalar que, en una gran mayoria de valoraciones, la intervención de factores intelectuales ocurre a través de la aceptación y uso de patrones estimativos, lo que basta para probar la importancia de su función axiológica.

2.251. No menos importante que la conceptual es por cierto la función judicativa en la conciencia valorativa. En verdad, puede decirse que no hay valoración propiamente dicha mientras el sujeto no llegue a formular un enunciado estimativo, aunque éste no se dé temáticamente como foco de una apercepción o reflexión.

De esta suerte, pueden distinguirse las vivencias puramente reactivas, es decir, sin intencionalidad o toma de posición consciente, de las evaluativas, en que una instancia objetiva es temáticamente asumida y calificada. ${ }^{6}$

2.252. El resultado de la función judicativa son enunciados que tienen la forma predicativa de $\mathrm{X}$ es bueno, donde bueno ( $\mathrm{u}$ otra palabra análoga) opera como predicado de valor. A través de estos enunciados se exteriorizan y comunican las atribuciones de valor que, como tales y en principio, pertenecen al fuero interno del sujeto.

Dichos enunciados predicativos poseen todas las características lógicas de las proposiciones $y$, en consecuencia, son afirmativos o negativos, verdaderos o falsos.

2.253. Los patrones de valoración proporcionan los criterios mediante los cuales, normalmente, se califica a los objetos valorados. Un criterio de calificación es así una característica que, según el patrón, corresponde a la cosa buena (del género considerado). Por ejemplo, si alguien afirma que una refrigeradora es buena, puede sostener que lo hace en vista de que dicho

5 También este importante tema podrá ser encarado en una mejor luz gracias a las distinciones que se introducirán en la mencionada sexta parte.

- Brentano y Scheler han puesto de resalto esta diferencia, aunque no lleguen a recono. cer -especialmente el segundo- la esencial función del juicio en la valoración. Desde este punto de vista, Scheler retrocede en relación con Husserl. 
artefacto tiene descongelación automática, que es una de las características comprendidas en el patrón de valoración correspondiente. La aplicación de los criterios de valoración implica el establecimiento de una correspondencia entre el criterio y las características del objeto, o correspondencia fácticoaxiológica.

2.254. A propósito de la verdad y la falsedad en la valoración, señalemos la posibilidad de que un sujeto afirme que algo es valioso y luego viva la experiencia de que estaba equivocado. Frases como Creí que Juan era bueno, pero estaba equivocado o Me engañé sobre el valor de esa joya no son nada insólito en el lenguaje valorativo cotidiano. Esta inserción del concepto de error en la atribución de valor puede ocurrir de dos maneras. De ellas, una no compromete el aspecto propiamente estimativo de la experiencia mientras que Ia otra sí tiene esta consecuencia. En efecto, un sujeto puede incurrir en error sobre el valor de un objeto porque tiene una representación falsa de él. En este caso, la falsedad sobre las propiedades del objeto lleva a una atribución de valor inadecuada. Como se comprende, el error es aquí primariamente de conocimiento y valorativo sólo de modo derivado. Puede ocurrir, en cambio, que estando el sujeto perfectamente informado de las características efectivas del objeto, lo juzgue bueno y luego reconozca su error producido porque habia aplicado indebidamente al objeto un concepto de cosa buena que, en verdad, no reconoce como tal. Por ejemplo, alguien que juzgue a los promotores de grandes monopolios como buenos ciudadanos, podría recapacitar luego sobre el concepto de buen ciudadano y sobre aquello que hace bueno un ciudadano, y considerar que las características del promotor de trusts no se adecúan a tal concepto. Dirá entonces: "Creía que los grandes monopolistas eran buenos ciudadanos, pero estaba equivocado." En este segundo caso, podemos hablar de un error primaria y propiamente valorativo.

2.26. En relación con el error valorativo conviene mencionar otros fenómenos, que son como formas aberrantes de la vivencia de atribución, cuyo análisis detallado merece un estudio especial. Llamamos la atención especialmente sobre la ilusión valorativa, la falsificación y la mistificación de los valores. Sin pretender llegar a detalladas precisiones, cabe señalar en el primero la presencia de una creencia en el valor de algo, que sin embargo no posee las características adecuadas a la calificación de bueno, pero que parece tenerlas por la acción, casi inevitable, de diversos factores psicológicos y situacionales. En el límite se confunde con el error; pero mientras éste puede darse sin constricción ni forzosidad, en la ilusión el sujeto es, por decirlo así, capturado por el engaño. Compárese, por vía ilustrativa, las ilusiones visuales bien conocidas en la psicología, en las cuales ocurre también esta suerte de error inevitable. Cuando hay ilusión valorativa, el sujeto está, pues, 
sometido a la acción de ciertos factores que hacen que su juicio espontáneo e inicial sea equivocado. Se dice, en este sentido, que las madres se hacen siempre ilusiones sobre las virtudes de sus hijos. Otro caso de ilusión es el que provocan las falsificaciones. Veamos en qué consisten éstas desde el punto de vista valorativo.

2.262. La clasificación o inautenticidad comporta la sustitución de un objeto por una copia, remedo o versión ilegítima de él. Cuando alguien atribuye valor a un objeto falsificado cae en una ilusión. Pero puede tener la vivencia de la falsificación; entonces juzga al objeto no como algo completamente malo o con tal o cual grado de valor ordinario, sino justamente como falsificado. De donde se colige que falsificado es un término con sentido también -y quizá primariamente- valorativo.

2.263. Finalmente, la mistificación consiste en la sustitución total o parcial de un objeto por otro en la atribución de valor, sin que el sujeto tenga conciencia del cambio. Ocurre frecuentemente en la propaganda comercial; por ejemplo, cuando conduce al público a comprar un producto, digamos un jabón, que sirve para un uso determinado, en vista del prestigio social que entraña el usarlo o de los premios que pueden obtenerse en la lotería organizada por los fabricantes. En este ejemplo simple y banal se ve que el valor atribuido al jabón propiamente se refiere a otras cosas que subrepticiamente lo sustituyen en la conciencia del sujeto.

2.27. Con respecto a la inferencia vinculada a la atribución de valor es pertinente recordar que desde antiguo se ha observado que sólo cabe extraer conclusiones estimativas de premisas en las cuales haya por lo menos un enunciado estimativo. Lo que Max Black llama "la guillotina de Hume", a saber, que todo intento de llenar el vacío entre formulaciones constativas y valorativas está condenado al fracaso, pues entraña un vicio lógico, tiene aquí su lugar propio. Con lo cual se precisan ciertos rasgos esenciales y determinadas condiciones y límites del razonamiento en la experiencia del valor. Según ellas, la conciencia discursiva en la valoración no puede ser reducida a las formas del discurso fáctico, sino que tiene su carácter y dominio peculiares.

2.30. La conciencia afectivo-conativa es también momento esencial de la vivencia de atribución de valor, pues ésta comporta siempre una inclinación a favor o en contra del objeto y una reacción afectiva concomitante. Tomemos por lo pronto este factor en su más amplia generalidad, es decir, como una clase que incluye estados, tendencias, sentimientos, inclinaciones, deseos, etcétera. ${ }^{7}$ Sin tener que suscribir ninguna tesis intuicionista, del tipo de las de Brentano o Scheler, ni la distinción formulada por este último entre senti-

7 A esta amplitud y variedad de hechos anímicos quiere Perry que corresponda el término "interés" que él propone como principal en el lenguaje de la psicología axiológica. Cf. General Theory of Value, Cambridge University Press, 1954, cap. v, 49, p. 115. 
mientos intencionales y meros estados afectivos, ${ }^{8}$ puede reconocerse la presencia de afectos y vivencias activas orientados en relación con un objeto, justamente el objeto de que se tiene conciencia en la valoración, que, según hemos dicho, es un elemento indispensable en ella. Basta con establecer la existencia de este momento constativo para asegurar la intencionalidad de los efectos y tendencias estimativos, por oposición a las vivencias ajenas a esta referencia o con término objetivo vago, mientras que la tesis scheleriana comporta todos los peligros del intuicionismo y, en mucho, bordea los linderos de la parapsicología o de la psicología especulativa.

2.31. Importa subrayar, a propósito del momento activo aquí implicado, que él cumple una función propia en la medida en que se inscribe en una vivencia definida como inclinación favorable o rechazo. No basta, pues, tener un movimiento hacia un objeto, como podría ser v.gr., el de señalar un color a pedido de alguien, para que se dé un caso de conducta atributiva de valor, pues fácilmente se comprueba que tal acto puede ejecutarse sin ninguna disposición favorable o contraria al objeto.

2.32. En suma, encontramos vivencias afectivas del más diverso carácter (placeres, agrados, alegrías, molestias, amor, odio, etc.), intencionalmente dirigidas a un objeto y a sus propiedades, por efecto de la acción concomitante de la conciencia constativa del objeto, y formas conativas de la conducta, teñidas por los afectos mencionados y determinadas básicamente como movimientos a favor o en contra de un objeto.

2.321. Conviene considerar en este contexto la controversia suscitada desde la Antigüedad por la función asignada a los placeres, agrados, gustos y, sus contrarios, los dolores, desgrados y disgustos, en el fenómeno valorativo. Hay, de un lado, filósofos que conceden una enorme importancia a este factor, hasta el punto de considerarlo la clave no sólo de la vivencia valorativa sino incluso de la naturaleza del valor. Para ellos, una y la misma clase de respuestas corresponden a la cuestión de cuál es el carácter de los actos que el sujeto vive cuando valora y a la cuestión, muy diferente sin embargo, de cuál es el fundamento de la valoración. Es frecuente encontrar, bien que con variantes múltiples, un tipo de posición como éste entre los filósofos anglosajones del pasado y del presente, generalmente defensores de tesis subjetivistas, pero no sólo de ellas. De otro lado están quienes sostienen la irrelevancia de tales vivencias para la comprensión del fenómeno del valor. Extremando la nota polémica, se llega en ciertos casos a postular una total independencia de la conducta estimativa, cuando menos en sus formas más altas, con respecto al placer y a los demás fenómenos afines que mencionamos arriba. El kantismo, en sus momentos ascéticos, llega a posiciones de este tipo, de las que no están tampoco lejos muchos otros filósofos de cepa apriorista, como es el caso de Max Scheler.

8 Cf. Scheler, Der Formalismus, segunda parte, sección quinta, cap. $1^{\circ}, 2$. 
No es difícil mostrar que ambas tesis extremas, teniendo el mérito de llamar la atención sobre un aspecto muy importante de la vivencia de valor, al acentuarlo en perjuicio de otros aspectos, deforman la experiencia y provocan pseudoproblemas de interpretación. En efecto, hay siempre, como una constante empírica, un elemento de placer o displacer, de agrado o desagrado, de gusto o disgusto en la vivencia valorativa, pero esta presencia no permite confundir la cuestión de la naturaleza y fundamento del valor con una cuestión psicológica ordinaria.

Ateniéndonos a los datos descriptivos puede decirse, creemos, lo siguiente sobre la función de tales elementos afectivos.

2.322. Los afectos de que hemos hablado se ofrecen de ordinario como hechos concomitantes, como elementos que acompañan a los actos de valoración. Esto puede ser establecido, igualmente, por una amplia experiencia. Podría inclusive pretenderse que, de acuerdo a los datos hasta ahora reunidos, siempre, en una u otra forma, se hará presente en la valoración un placer, un agrado o un displacer, un desagrado, un gusto o disgusto. Pero, al mismo tiempo, hay que reconocer que con ello no se ha concedido que el fenómeno del valor sea identificable con la vivencia de placer, ni que tener agrados o disgustos equivalga sin más a apreciar el valor de algo, y menos aún que el placer y el gusto equivalgan a lo bueno. Bien podria ocurrir que estos hechos coincidentes y concomitantes se comprobaran en todos los casos y que, sin embargo, la naturaleza y el fundamento del valor no tuvieran que ver con ellos. En todo caso, debe quedar claramente establecido que una cosa es describir la vivencia del valor y otra plantear y resolver el problema del fundamento del valor.

2.323. Descriptivamente, cabe sin embargo reconocer otra función al placer y al dolor, al agrado y al desagrado, al gusto y al disgusto. No es difícil comprobar, en efecto, que en la mayoría de los casos ellos motivan las valoraciones de los hombres. En este sentido, puede decirse que la vivencia estimativa - por lo menos en un gran número de casos- se origina y se apoya en dichos afectos. Podemos usar la pareja clásica: ratio essendi y ratio cognoscendi, para precisar mejor el alcance de esta función motivadora. Como se sabe, la diferenciación de una y otra ratio en filosofía tiende a poner de resalto el hecho de que aquello que es modo o vehículo de conocimiento, pese a cumplir un papel importantísimo en la determinación de los objetos, no es sin embargo un fundamento o causa de ser.

Esto es justamente lo que ocurre en la valoración. Los afectos señalados pueden funcionar, y de ordinario funcionan, como ratio cognoscendi del valor, lo cual se comprueba en la más variada gama de experiencias. Pero de ello no se sigue, en lo más mínimo, que tengan la función de fundamento del valor, ni siquiera de la valoración en cuanto implica un reconocimien. to de exigencias. 
2.324. En tercer lugar, debe repararse en el hecho de que en unos casos -que son los examinados hasta aquí- el placer y los demás afectos considerados son elementos de la vivencia valorativa, pero en otros son más bien objeto de la valoración. No es raro sino frecuente el preguntar apreciativo enderezado al grado o al desagrado, al dolor o al placer, al gusto o al disgusto mismos, con lo que se muestra, desde otro ángulo, la diferencia entre la función de motivador o acompañante y la función de fundamentador con respecto a los mencionados afectos. Porque no cabe ciertamente aceptar la coexistencia de la función de fundamento, $v$. gr., del placer, y la pertinencia de preguntas sobre el valor del placer o de tal o cual placer particular, que son muy comunes.

2.33. También se ha subrayado desde antiguo la importancia del deseo en la conciencia atributiva de valor. Con respecto al carácter y función de esta vivencia valen las consideraciones arriba hechas a propósito del placer, el gusto, el agrado y sus contrarios. El caso del deseo ofrece, sin embargo, una magnifica coyuntura para aclarar y enfatizar por medio del análisis lingüístico la diferencia que hay entre las vivencias de atribución de valor y las vivencias constativas con referencia psicológica. Es evidente que cuando hay una valoración positiva de un objeto, puede ésta traducirse mediante una frase en que aparezca la expresión deseado. Cabe inclusive decir que prácticamente en todos los casos esto ocurre y hasta que debe poder hacerse la referida traducción. La situación cambia enteramente, sin embargo, cuando atendemos a otra palabra, afín a la anterior, pero cuyo sentido, en el uso ordinario, no se reduce a la mera función constativa: la palabra preferible. Como otros términos gerunditivos, hay en ella un elemento semántico que implica la comunicación de una exigencia, de una cierta autoridad, ausente en las expresiones meramente fácticas. ${ }^{9}$ Puesto que en las vivencias valorativas hay seguramente siempre un deseo, puede decirse que el objeto valorado siempre es deseado; pero el peso propio de la atribución de valor y su diferencia respecto de la mera comprobación psicológica está en que sólo a aquello que se atribuye valor - $y$ no que es meramente deseado- se le puede calificar de deseable, esto es, de digno de ser deseado.

2.41. Las inclinaciones favorables o desfavorables al objeto tienen en las vivencias de atribución de valor el carácter de una oposición polar estricta. Hay un pro, un movimiento, siquiera potencial o meramente mental, en dirección al objeto, una aceptación de él; de otra parte, en el extremo opuesto, hay un contra, un movimiento de alejamiento del objeto, un rechazo. Los actos de atribución pueden por tanto calificarse siempre como posilivos o negativos, siendo $\mathrm{X}$ es bueno y $\mathrm{X}$ es malo los modelos de enunciados polarmente opuestos, uno positivo y el otro negativo. Esta polaridad es un rasgo

- Cf. infra 2.51, en donde consideramos este elemento sui generis de exigencia. 
indispensable y universal de la experiencia valorativa, hasta el punto de poder decirse que nunca puede faltar cuando ocurre una valorización.

2.42. Cabe, sin embargo, matizar este enfoque y utilizar un registro psicológico más rico al describir las vivencias de atribución. En efecto, hasta ahora nos hemos movido en el terreno de lo que podemos llamar la atribución simple de valor, que consiste en calificar a un objeto como positiva o negativamente valioso, como valioso o desvalioso. Pero en la experiencia es muy frecuente $-\mathrm{y}$ seguramente la más frecuente- una vivencia diferente, que vamos a llamar de atribución graduada de valor. Cualquiera puede verificar en su propia conducta que las actitudes evaluativas cotidianas no califican a los objetos solamente de bueno o malo, o de valioso o desvalioso, sino que operan con un registro más variado de calificaciones, como son, a saber, las expresadas por términos como excelente, muy bueno, regular, mediocre, pésimo. La conciencia valorativa usa los superlativos muy frecuentemente, y esto quiere decir que gradúa su atribución de valor. Hay, pues, una función de graduación propia de esta conciencia. Vista desde tal perspectiva, la oposición polar de bueno y malo se ofrece como el contraste de dos actitudes atributivas, cada una de las cuales puede darse con una mayor o menor acentuación y nitidez, quedando entre ambas la línea medianera, muy difícil de determinar por cierto, de una conciencia pura, neutral o indiferente. ${ }^{10}$

2.430. Puede decirse que los contrastes polares y la diferenciación de atribuciones graduadas de valor se ofrecen como una oposición estricta, entendiendo por esto una situación vivencial tal que si alguien atribuye un valor positivo o un determinado grado de valor a un objeto no puede atribuirle el valor negativo correspondiente $\mathbf{u}$ otro grado de valor, al mismo tiempo y en el mismo respecto. Por ejemplo, nadie puede decir que un auto es bueno y malo, refiriéndose al mismo término intencional, en un mismo momento, o que es muy bueno y regular en las señaladas condiciones. Vamos a llamar al enunciado de esta incompatibilidad el principio de la oposición estricta de los polos y grados en la atribución de valor. De lo anterior se sigue que la variación polar o de grado en la atribución de valor sólo es posible en la medida en que se produce un cambio en el objeto. Si v. gr., un florero es considerado muy valioso, sólo puede ser juzgado mediocre o sin mayor valor cuando ha sufrido algún daño o alteración que afecta su figura o su materia.

Cabría, sin embargo, observar que hay casos en que varía la atribución de valor a pesar de que el objeto permanece incambiado. Por ejemplo, un automóvil que antes era considerado bueno, ahora es menos apreciado, a pesar de no haber prácticamente cambiado. ¿Desmiente esto el principio de la oposición estricta de la polaridad y la graduación? Creemos que no, pues

10 La polaridad y la graduación tienen que ver con la jerarquización que estudiaremos más adelante. Cf., infra 4.50 . 
son posibles cuando menos dos explicaciones de tales casos, concordantes ambas con el principio de la oposición. Veámoslas más de cerca.

2.431. El primer caso es el siguiente: El auto no ha variado, pero ha variado nuestro conocimiento de él. Sabemos ahora que tiene tales o cuales carácteres, antes ignorados, los cuales afectan su rendimiento. Como se ve, aquí, indirectamente, se trata también de una variación del objeto, por lo menos en cuanto es conocido, lo cual repercute sobre la atribución de valor.

2.432. El segundo caso es el siguiente: el auto no varía ni aumenta nuestro conocimiento de sus características, pero cambia el concepto de auto bueno implicado en la atribución de valor. El auto puede ser, por ejemplo, un modelo. " $T$ ", perfectamente conservado, al cual hace muchos años consideramos muy bueno; hoy no lo juzgamos así sino regular o simplemente bueno, porque nuestro concepto de lo que es un auto bueno ha variado entretanto.

2.51. Señalemos, por último, la presencia de un factor de exigencia en la atribución de valor. Cuando, por ejemplo, alguien dice que una pieza de teatro es buena, pretende formular una afirmación que en principio debe ser compartida por todos los que se hallan en la situación pertinente; se trata de una afirmación que se quiere fundada y con derecho a reclamar aceptación unánime. De allí que, ante una opinión opuesta, surja naturalmente la discusión, alimentada por el deseo de establecer la verdad y por la creencia en la posibilidad de convencer al otro. Pero cuando el sujeto depone esta actitud, con su voluntad implícita de acuerdo racional, tiende a desechar formulaciones como la mencionada y a sustituirlas por otras de sentido diferente, como, v. gr., A mí me gusta esa pieza de teatro. Muchas veces esta afirmación es acompañada de frases que generalmente matizan o disminuyen la fuerza de la enunciación, como son: "de cualquier modo", "por lo menos", "sea como fuere", "a mí me gusta", etc.

2.52. Este factor de exigencia se manifiesta subjetivamente por intermedio de la vivencia de una atracción o de una cierta autoridad que el objeto ejerce sobre el sujeto, y objetivamente como una postulación de validez universal, ${ }^{11}$ lo cual da a la experiencia estimativa un carácter fenomenológicamente muy contrastado con respecto a las vivencias ordinarias tocantes a hechos internos o externos.

2.53. En relación con lo que acabamos de decir se comprende el uso del término "estimable" para calificar a todo objeto al que se atribuye valor, a diferencia de las menciones fácticas del mero estar siendo o haber sido objeto

11 Podría pensarse que el uso frecuente de expresiones del tipo de " $\mathrm{X}$ es bueno para mi" (o como él, para nosotros, etc.). desmiente nuestro análisis. No es difícil, sin embargo, mostrar, como lo hemos hecho en otro lugar, que ninguno de los varios sentidos en que se emplean las frases estimativas con "para" contradicen nuestra afirmación, pues expresan sea circunstancias, sea adecuación, sea limitación de conocimiento u opinión, elementos todos que no afectan a la exigencia. Cf. "La plurivocidad de 'bueno'". Critica, México, № 1. 
de un afecto. Esto quiere decir que hay un sentido fuerte de "estimable", que es compatible sólo con la vivencia de una exigencia universal.

2.54. Sin perjuicio de distinguir, cuando sea necesario, la conciencia valorativa y la conciencia del deber o de la obligación (especialmente moral), vamos a dar el nombre de normatividad a este elemento de exigencia reconocible en los actos valorativos. Atendiendo a tal elemento se confirma la diferencia entre conciencia constativa y conciencia estimativa que mencionamos al comienzo de este trabajo, así como la antigua oposición de las afirmaciones sobre hechos y las afirmaciones sobre valores.

2.6. Es frecuente la atribución múltiple de valor a un mismo objeto por un mismo sujeto. En este caso cabe encontrar diferentes atribuciones dirigidas simultáneamente al mismo objeto en el mismo respecto, o diferentes atribuciones referentes a distintos aspectos del objeto. $\mathrm{Y}$ las atribuciones mismas pueden ser de distinto género. Por ejemplo, un sillón puede ser calificado de bueno como objeto de arte y de malo como asiento, por el mismo sujeto y justamente en el mismo respecto; o puede ser calificado de bueno en su diseño y malo en su material; así como puede ser considerado bello, útil, sagrado, etcétera, en el mismo o en diferentes respectos. Por lo demás, como es obvio, existen también atribuciones múltiples de valor por diferentes sujetos, que pueden ser coincidentes o divergentes en mayor o menor grado.

2.7. La atribución múltiple de valor debe distinguirse de la atribución paralela de valor, que consiste en la calificación simultánea de varios objetos, semejantes o diferentes en mayor o menor medida, por un mismo sujeto. La atribución paralela como tal no implica comparación de los objetos valorados, ni siquiera tener el sujeto conciencia de que están siendo evaluados contemporáneamente por él. El olvido de las apreciaciones o la complejidad y abigarramiento de la experiencia explican esta situación y también las confusiones y mistificaciones frecuentes en la vida valorativa.

En orden a completar el cuadro de posibles actos plurales de atribución, señalaremos que también aquí, como es obvio, hay que considerar la existencia de atribuciones paralelas de varios sujetos, de las que eventualmente puede ser consciente cada uno de ellos.

2.8. Con lo anterior se vincula directamente el conflicto de valoraciones que ocurre cuando se oponen entre sí las atribuciones múltiples o paralelas de valor de un sujeto (y a veces de varios). El conflicto supone la conciencia de esta oposición de valoraciones.

Dejamos sin tocar, por el momento, la manera cómo se solucionan de ordinario los conflictos de valoraciones y en qué medida su solución requiere de una elección valorativa o puede cumplirse por otros medios. ${ }^{12}$ 
3.o. La realización del valor

3.11. Un acto de atribución de valor puede darse por consumado y completo sin que ninguna modificación del mundo exterior sea efectuada por el sujeto valorante. Esta prolongación o consecuencia externa de la vivencia ocurre, sin embargo, en ciertos actos estimativos que, por esta razón, deben ser distinguidos de los hasta aquí estudiados. Por ejemplo, el trazar un pintor determinadas formas en una tela, el dar limosna a un mendigo y el declarar ganador de un concurso literario a un escritor, si se obra en todos estos casos con la conciencia del valor de lo que se efectúa, son ejemplos de la conducta que queremos destacar. La llamaremos realización del valor, para emplear una denominación ya introducida en la literatura axiológica. Por cierto que con este uso no intentamos quebrar la norma antes formulada de mantenernos al margen de las teorías interpretativas, ni abandonar la actitud descriptiva y analítica en que nos situamos. Conviene por eso definir con alguna precisión el término.

3.12. Entendemos por realización de valores todo acto que traduzca, por una intervención en la realidad de cualquier género, la atribución de valor de un sujeto. El operar sobre la realidad, el modificarla o alterarla, el construir algo en ella, asi como el promover conscientemente conductas, el perseguir y alcanzar fines y el asumir determinadas consecuencias valiosas derivadas de nuestra conducta, son todos aspectos y formas de la realización del valor en el sentido arriba definido.

3.13. Alguien podria pensar, contra esta amplitud de la connotación asignada a la palabra realización, que hay una marcada diferencia, por ejemplo, entre el pintar un cuadro y el declarar ganador de un concurso literario a un escritor. Se diría que, mientras que en el segundo caso existe sólo una expresión verbal de una atribución de valor, en el primero hay una operación que transforma al mundo e instala en él lo valioso. Según esto, si se llama realización de valores a los actos del tipo del pintar, no puede decirse lo mismo de los ejemplificados por el otorgar un premio.

Tres cosas pueden aducirse en respuesta a esta observación. En primer lugar, que la distinción sugerida puede implicar -o proponer inconscientemente- una tesis sobre el valor, según la cual éste es como una propiedad, esencia o substancia que se instala en la realidad mediante determinadas operaciones, tesis que es discutible y que, en todo caso, no puede ser asumida al formular una distinción fenomenológica. La segunda y la tercera réplica se apoyan en la descripción de los actos. Cuando alguien otorga el primer puesto de un concurso a un escritor, está ejecutando un acto que puede ser calificado de bueno o malo y preferido a otros. Es, en el sentido más lato, una instancia objetiva apreciable y preferible. Ahora bien, no es lo mismo apreciar y preferir dicho acto que cumplirlo. El paso de un estadio a otro 
corresponde a la diferencia que se establece entre el considerar que una forma es bella o preferirla a otras como más bella, y el pintarla, diferencia que consiste justamente en una intervención en el mundo. Esta intervención, opuesta en ambos casos a la mera apreciación o preferencia, es lo que llamamos realización. Lo dicho se reafirma - tercera réplica- considerando que no cabe establecer una diferencia suficiente entre la intervención en la realidad, que ocurre en el pintar, y la que ocurre al otorgar un premio, puesto que los efectos de éste pueden ser mayores que los del pintar. La mera declaración de una opinión - por ejemplo, por un político en un mitinpuede determinar cambios mucho más grandes que una manipulación localizada. La omisión o abstención de actuar puede ser una forma muy eficaz de provocar cambios en el mundo. Por esta razón preferimos usar el término de "realización" para cubrir todas las intervenciones en la realidad, conscientemente ejecutados, por las cuales se alcanza un fin o se produce una consecuencia valiosa.

3.14. Consideramos separadamente los principales caracteres de la realización del valor de acuerdo a la definición anterior, contrastándola con la atribución valorativa. En primer lugar, la existencia de una prolongación exterior del acto, indicada antes repetidas veces. Esta prolongación es siempre, de algún modo, una modificación del mundo con el cual está en contacto el sujeto, mientras que en la atribución de valor no se comprende tal modificación. Lo dicho no impide reconocer diferencias en la intervención en el mundo, según grado y modos, que van de la mera acción verbal a la franca creación de una novedad óntica.

3.15. En segundo lugar, mientras la atribución de valor puede tener como términos intencionales instancias tanto reales cuanto ficticias, presentes, pasadas o futuras, la realización requiere términos efectivos o en trance de efectuarse, en el presente o en el futuro inmediato.

3.16. En la realización hay siempre un elemento o factor en trance de efectuación por obra del sujeto. De acuerdo a los datos descriptivos, lo que se efectúa es un objeto, una propiedad, estado o parte de él, o un modo de ser y actuar del sujeto en el mundo, valorativamente calificado.

3.17. En esta vivencia valorativa se da no solamente un concepto del objeto actual, o, dicho de otro modo, del mundo como es, sino también el concepto de una posibilidad objetiva que coincide con el concepto del objeto bueno - a que nos referimos antes- y que hay que realizar. Así, mientras en la atribución de valor se comprueba la existencia de un objeto que corresponde al concepto de objeto bueno y se reconoce una exigencia de validez de la atribución, aquí se comprueba una ausencia y se asume una exigencia de cumplimiento de ciertos actos y hechos.

3.18. La realización de valores comporta un elemento indispensable de decisión voluntaria y consciente de intervenir en el mundo, sin el cual no 
habria efectuación asumida y buscada por el sujeto de aquello que se considera valioso.

3.19. Estrechamente vinculada con lo anterior reconocemos una conciencia (constativa) de aquellas condiciones y expedientes gracias a los cuales puede efectuarse la objetividad buscada, es decir, una consideración, implícita o explícita, de los medios y circunstancias pertinentes para el logro de los fines valiosos perseguidos.

3.21. No será difícil encontrar casos de actos de realización de valor que no presenten un claro momento de decisión voluntaria. Puede ocurrir, por ejemplo, que alguien, sometido a una acción violenta, ejecute determinados actos que comportan la realización de un objeto o situación valorada, no sólo por otros sino también por él mismo. Formalmente, este acto coincide pues en mucho con los que hemos examinado en el anterior, salvo en este aspecto volitivo.

Creemos, sin embargo, que estrictamente hablando, tal falta supone una ausencia del agente personal, pues el sujeto funcionaría casi automáticamente $y$, en cierto modo, fuera de la situación. De alli que prefiramos considerar como actos de realización de valor, en sentido propio o fuerte, sólo los primeros, y tener a los segundos por realizaciones de valor en sentido impropio o débil.

3.22. Por contraste con lo que ocurre en los actos de realización de valor en sentido impropio, donde hay una efectuación de lo valioso, aunque no voluntaria, que coincide con un valor reconocido por el sujeto, existen casos en que la efectuación -voluntaria en lo esencial- no coincide con la atribución de valor que el sujeto acepta en su fuero interno. El sujeto pretende estar realizando un valor que, sin embargo, no reconoce. Por ejemplo, si en una comunidad muy piadosa, en que todos sus miembros atribuyen valor positivo religioso al asistir a los oficios de la iglesia, las personas que no reconocen tal valor pero concurren a los oficios, como lo hacen los practicantes del culto, están ejecutando un acto en lo sustantivo distinto al que cumple el creyente. Diremos que en éste hay autenticidad de conducta, mientras que la del primero es inauténtica. Según esto, hay realizaciones de valor auténticas e inauténticas.

Repárese en que aquí se halla implicado un elemento de engaño. Sin embargo, el caso de la inautenticidad en la realización del valor no se reduce a las formas estudiadas al tratar la atribución de valor. ${ }^{13}$ En ésta, como sabemos, no hay siempre exteriorización ni modificación de la realidad. Lo nuevo en el caso de la realización es justamente la acción sobre el mundo. La inautenticidad en la realización, suponiendo el engaño -que como tal puede quedar reducido a una mera declaración-, va más allá en tanto que comporta una intervención o una abstención de intervenir en el mundo.

13 Cf. los parágrafos $2.222,2.261,2.262$ y $2.26 g$. 


\section{4.o. La preferencia y la postergación}

4.1. El preferir y el postergar consisten en un acto o vivencia de apreciación comparativa de grados de valor referentes a dos o más instancias objetivas. Ejemplos ordinarios de preferencia son el juzgar mejor una fruta que otra, el encontrar más perfecto un cuadro que otro; ejemplos de postergación son, correlativamente, el considerar una fruta tan buena como otra y el juzgar un cuadro inferior estéticamente a otros. En vista de que no existe un término común que cubra ambos casos, por economía, en lo que sigue, al tratar del preferir y el postergar simultáneamente haremos referencia sólo al primero, salvo los casos en que sea necesario señalar diferencias.

4.2 1. Notemos que es rasgo característico del preferir el estar dirigido no a uno sino a varios objetivos. Éstos pueden ser dos o más instancias reales, imaginarias, presentes, pasadas o futuras (con la amplitud que, según vimos, corresponde a la atribución de valor), o aspectos de estas instancias $o$, en fin, a la misma cosa en varias circunstancias de lugar o tiempo. Se prefiere, v. gr., una casa a otra, un personaje de novela a otro, Napoleón a Metternich, o una parte de una casa a otra, Napoleón en Jena a Napoleón en Waterloo, la casa tal como era en 1945 a la casa tal como es en 1965 , etc.

4.22. Se puede decir que, si bien no de modo necesariamente explícito y definido, hay en la preferencia tantas vivencias de atribución de valor cuantos términos objetivos entren en consideración. Tales atribuciones paralelas o múltiples de valor constituyen a modo de base sobre la que se asientan el preferir y el postergar. Así, por ejemplo, habrá un valorar tácito referido a Napoleón y otro referido a Metternich como condición de la preferencia del primero sobre el segundo. Por cierto que no es necesario que se den previamente dos vivencias de atribución numéricamente distintas y aisladas; basta con que analíticamente puedan pensarse como condiciones implicadas en el acto de preferir. ${ }^{14}$

4.32. Llamamos la atención aquí sobre la diferencia señalada por Von Wright entre un preferir que procede considerando las razones que hacen a un objeto mejor que otro y que se basa por tanto en un juicio atributivo de valor, clase de preferencia que el mencionado autor llama extrinseco, y un preferir en el que no interviene la opinión que el sujeto tiene sobre el valor del objeto, sino que consiste en el gustarle más un objeto que otro; esta segunda clase de preferencia la llama Von Wright intrinseca. ${ }^{15}$ Preferir ex-

14 Con este tema se vincula la cuestión, tratada en el parágrafo 2.01, de la prioridad de la atribución de valor con respecto a otras formas de vivencia estimativa, entre las cuales se cuenta el preferir.

15 Georg Henrik Von Wright, The Logic of Preference. An Essay. Edimburgh, at the University Press, 1963, págs. 14 ss. La teoria formal expuesta en este sugestivo trabajo se limita al caso de la preferencia intrínseca. Sin embargo, es aprovechable independientemente de esta restricción. 
trínseco sería, por ejemplo, el considerar mejor un vino que otro en vista de su antigüedad, su color, sus efectos fisiológicos, etc.; en cambio, sería intrínseco el gustar más de un vino que de otro. En este segundo caso, para Von Wright, la preferencia sería constitutiva de la condición de mejor que (betterness) del objeto. Y no cabría decir que el sujeto prefiere un vino a otro porque le gusta más, por la siguiente razón: que gustar más y preferir es entonces la misma cosa. ${ }^{16}$

Esta distinción merece un examen minucioso porque parece correspon. der a un vasto uso del lenguaje $y$, por lo tanto, a una amplia experiencia. Es muy común, en efecto, hablar de la preferencia como de gustar más una cosa que otra. Reparemos sin embargo en que, ateniéndonos a los resultados de nuestro examen de las bases del preferir, aceptar que preferir significa lo mismo que gustar más nos llevaría a considerar que atribuir valor a algo es, eo ipso, lo mismo que gustar de ello. Éste, sin embargo, no es el caso, pues, como sabemos, hay una diferencia fenomenológicamente muy marcada entre el elemento de normatividad que acompaña a una atribución propia de valor y la ausencia de esta demanda en los juicios psicológicos del tipo de "Me gusta X" o "Nos gusta X". Descriptivamente considerado, un enunciado del tipo de " $\mathrm{X}$ me gusta más que $\mathrm{Y}$ " es un enunciado psicológico, como lo son "Estoy más contento cuando veo a $X$ que cuando veo a $Y$ " $y$ "Me entristece la victoria de $\mathrm{X}$ y me alegra la de $\mathrm{Y}$ ", en los cuales no se comunica ninguna exigencia normativa.

Es obvio que la cuestión aquí tratada puede decidirse también como un problema de definición de términos. Una vez aplicado este expediente y dados nombres distintos a cosas distintas, no cabe confundir la información sobre una experiencia interna, perfectamente reducible a un suceso individual, con la información sobre una experiencia que implica el vivir un momento de normatividad extraño a los referentes fácticos. Si cuando se habla del gustar más o menos se comunica algo distinto que la mera información psicológica sobre la vida interior, se está significando una preferencia en el sentido general y propio, aunque con un lenguaje que induce a confusión. Si no se significa esto y se trata de una mera información psicológica, entonces se trata de algo distinto al acto valorativo que estudiamos.

Por consiguiente, cabe y conviene hablar de una preferencia en sentido propio, que es una forma de la vivencia del valor, diferente del simple gustar más o menos, impropiamente llamado preferir.

4.33. Como una contraprueba de lo anterior, obsérvese la conducta del término "preferible", que es completamente distinta en el caso del uso vinculado con el preferir que hemos llamado propio y en el del preferir intrín-

16 Op. cit., págs. 14-15. Es interesante notar que Von Wright aclara la expresión inglesa "to like better" (que traducimos por gustar más), poniendo entre paréntesis, después del último término, la palabra "more". 
seco de Von Wright. "Preferible", en sentido valorativo fuerte, significa lo que debe ser o es digno de ser preferido, o sea, lo que debe ser estimado más que o antes que otra cosa, o que es digno de serlo. Se trata en buena cuenta de una calificación relativa exigible. En cambio, cuando se usa "preferible", en el contexto de un juicio de gusto, en relación con dos objetos posibles, no se ve con claridad qué cosa puede significar además de lo que comunica ya el término fáctico "preferido".

4.34. La distinción de Von Wright es, sin embargo, aceptable en otro sentido, que parece ser insinuado en su exposición, aunque no se llegue a distinguirlo bien del que hemos estado considerando. Se trata de la diferencia entre un preferir que se atiene a un examen previo de las características de los objetos juzgados y, eventualmente, a ciertas normas o patrones de valoración, y preferir que opera sin este trámite previo y que atribuye directa y como espontáneamente a un objeto un valor mayor que a otro. ${ }^{17}$ Así interpretada, podría mantenerse la diferencia entre un preferir extrinseco y uno intrínseco, entendiéndolos entonces respectivamente como un preferir con bases extrínsecas al acto y un preferir intrínsecamente fundado.

4.351. Es evidente que la polaridad y la gradación propias de la atribución de valor desempeñan un papel fundamental en el preferir. En efecto, si no es posible contrastar un pro con un contra y distinguir grados de calificación valorativa, no cabe decir que un objeto es mejor que otro. Repárese en que, como hemos señalado, al suponer la polaridad y la gradación, desde el punto de vista óntico; un más y un menos, una presencia y una ausencia de caracteres (puesto que en caso contrario no habría aquella variación del objeto necesaria para la oposición o la calificación graduada), la apreciación relativa propia del preferir atiende a tales ausencias y presencias, aumentos, disminuciones y número de caracteristicas.

4.352. En correspondencia con el principio de la oposición estricta ${ }^{18}$ de los enunciados polarmente opuestos y con graduación diferente, comprobamos en el caso de la preferencia que ésta es a su turno excluyente, o sea, que no se puede preferir o postergar simultáneamente dos objetos opuestos o de grado de valor diferente, ni preferir un objeto y postergar otro y, al mismo tiempo, considerarlos iguales en todos los respectos. Por lo tanto, para que se produzca la preferencia es preciso que dos o más objetos, o partes de un objeto, difieran en algún respecto o que un mismo objeto haya cambiado de un tiempo a otro o de una situación a otra.

Por otra parte, aplicando el principio mencionado, se dirá que dos objetos iguales han de ser ambos preferidos o postergados respecto a un ter-

17 No confundir esta diferencia con la tratada en 6.14, pues la espontaneidad de que aquí hablamos no excluye el hábito o la costumbre.

18 Cf. supra 2.430 . 
cero y no pueden ser preferido el uno y postergado el otro respecto a un tercero, salvo que ocurran variaciones por lo menos en uno de ellos.

Las aparentes excepciones al principio pueden ser resueltas en el caso del preferir del mismo modo que en el de la atribución de valor. ${ }^{19}$

4.353. Otra observación que merece ser consignada es la relativa a la conexión en que se encuentra la facilidad o dificultad del preferir con la equivalencia de los valores atribuidos a las instancias entre las cuales se prefiere. Puede decirse que, a medida que las instancias comparadas tienden a ser equivalentes en valor, la preferencia se hace cada vez más difícil, mientras que, a la inversa, la disimilitud en el valor atribuido elimina toda dificultad en la preferencia o la postergación. ${ }^{20}$

4.36. La preferencia y la postergación se formulan en un enunciado comparativo de valor, del tipo de "X es mejor que $\mathrm{Y}$ " o "X es peor que $\mathrm{Z}$ ", es decir, en un juicio relacional con dos o más sujetos. Como hemos dicho, estos sujetos lógicos pueden referirse, en ciertos casos, al mismo objeto tomado en circunstancias, estados, tiempos o aspectos diversos. Las relaciones establecidas entre tales términos tienen como propiedades formales, de acuerdo a Von Wright, ${ }^{21}$ la asimetría y la transitividad. Por consiguiente, si X es juzgado mejor que $\mathrm{Y}$ entonces $\mathrm{Y}$ no puede ser considerado mejor que $\mathrm{X}$. Si designamos a peor como la relación conversa de mejor, se dirá que si $\mathrm{X}$ es mejor que $\mathrm{Y}$, entonces $\mathrm{Y}$ es peor que $\mathrm{X}$. Por lo que toca a la transitividad, ella significa que si $\mathrm{X}$ es juzgado mejor que $\mathrm{Y}$ y si $\mathrm{Y}$ es juzgado mejor que $Z$, entonces $X$ será juzgado mejor que $Z$. El sentido de "mejor", es decir, de la relación establecida en el preferir, exige pues esta última afirmación. Repárese en que sólo si se entiende la preferencia como una apreciación comparativa del valor de dos o más instancias objetivas, y no simplemente como un gustar más, ${ }^{22}$ puede hablarse de la transitividad estricta de la relación de preferencia. En efecto, nada impide que alguien guste más de $X$ que de $Y$, y de $Y$ que de $Z$, y que, sin embargo, guste más de $Z$ que de $X$. Como hecho psicológico esto es perfectamente factible. Si preferir es simplemente gustar más, entonces el hecho de gustar más de $\mathrm{Z}$ que de $\mathrm{X}$, si se produce, es inapelable $y$, por tanto, la relación intransitiva. No es suficiente afirmar, como lo hace Von Wright, ${ }^{23}$ que en tal caso diremos que el sujeto

10 Cf. supra 2.430-2.433.

20 No toda preferencia supone un cierto esfuerzo; sólo algunas se ofrecen como preferencias, por decirlo asi, laboriosas. Éstas, sin embargo, deben ser distinguidas de lo que en el parágrafo 2.8 llamamos conflictos de valoración, cuya característica más saltante es la existencia de dos atribuciones paralelas que chocan entre si y que, en rigor, suponen aceptar y no aceptar a la vez el valor de un objeto. En cambio, en la preferencia difícil no hay tal choque del sujeto consigo mismo, sino un momento de suspenso, de sopesamiento o reflexión, previo a la formulación final al juicio comparativo.

21 Cf., op. cit., pág. 21.

22 Cf. supra 4.32-4.33.

23 Op. cit., pág. 22. 
ha cambiado de preferencia, porque cabe afirmar, sin contradiccion, que el sujeto sigue gustando más de $\mathrm{X}$ que de $\mathrm{Y}$ y de $\mathrm{Y}$ que de $\mathrm{Z}$, a pesar de gustar más de $\mathrm{Z}$ que de $\mathrm{X}$. Cosa diferente ocurre si entendemos el término "preferencia" en el sentido propio, definido en 4.32, pues al implicar ésta dos o más atribuciones de valor, los enunciados no se reducen a meras comprobaciones de hechos, sino que implican un elemento normativo que exige la transitividad. En este caso, pase lo que pase con las vivencias que fácticamente experimente, si el sujeto reconoce que $\mathrm{X}$ es mejor que $\mathrm{Y}$ y que $\mathrm{Y}$ es mejor que $\mathbf{Z}$, entonces tienen que afirmar, so pena de contradicción, que $\mathbf{X}$ es mejor que $\mathrm{Z}$.

4.37. No debe llevar a error sobre la supuesta reflexividad de la relación de preferencia el hecho de que puedan atribuirse diversos valores o grados de valor a un mismo objeto en diferentes circunstancias, tiempos, estados $o$ aspectos, y de que frecuentemente se comparen las correspondientes calificaciones. En este sentido, es posible decir que $\mathrm{X}$ es mejor que $\mathrm{X}$, pensando en $\mathrm{X}$ aquí versus $\mathrm{X}$ allá, o en $\mathrm{X}$ según determinado respecto $\mathrm{y} X$ según otro. Obviamente, no hay en este caso reflexividad estricta sino una relación diádica en que los términos son instancias objetivas diversas aunque referentes a $X$.

4.38. De todo lo anterior se colige fácilmente que los términos preferenciales más importantes, como "mejor", "peor", "superior a", "inferior a", etcétera, en cuanto se fundan en elementos semánticos que tienen que ver con aumentos o. disminuciones, presencias o ausencias de ingredientes o propiedades de las cosas, comportan un sentido complejo de más bueno que o menos bueno que, que define lo que en cada caso puede calificarse de preferible.

4.39. El concepto de la cosa buena (en su género) y, con él, el patrón de valoración, ${ }^{24}$ son mediadores en el juicio de preferencia. Como sabemos, ambos se refieren a un género de objetos, diverso en cada caso y, por tanto, a lo que es común a los varios objetos considerados en el preferir. Por ejemplo, cuando se prefiere una refrigeradora a otra, este acto se basa en una comparación de las propiedades poseídas por cada una de ellas; presupone, además, el reconocimiento de una comunidad de género en dichos objetos y una referencia especial a aquellas características que son consignadas en los criterios de valoración extraídos del patrón ( $v$. gr., capacidad, velocidad de refrigeración, etc.).

Esquematizada, la operación del juicio preferencial supone: I) La conciencia de determinadas propiedades comunes a ambos objetos, las cuales proporcionan la base de la comparación. 2) La referencia a una constelación

24 Otras relaciones formales correspondientes a la preferencia se encontrarán en el libro citado de Von Wright; son aprovechables plenamente, salvo en los casos en que se derivan de la distinción arriba criticada. 
de propiedades selectivamente consignadas en el patrón de valoración. 3) La determinación de las diferencias que ofrecen los objetos desde el punto de vista de sus propiedades. 4) La correspondencia fáctico-axiológica del caso.

4.392. No nos parece correcto postular la existencia necesaria de un patrón y de un concepto de lo preferible - como los hay con respecto a bueno-, entre otras razones porque serían vacíos o no podrian adecuarse a las circunstancias cambiantes de la comparación. Un concepto fijo de lo preferible no existe de hecho sino en muy contados casos de preferencia codificadas y tradicionales, que no constituyen, pues, regla.

4.41. Por lo que toca a los otros aspectos de la vivencia valorativa, el momento afectivo-conativo es indispensable en el preferir, el cual, en gran parte, depende del mayor o menor grado de la inclinación favorable o desfavorable. Hay siempre una afección y un enderezamiento activo mayor con respecto al objeto preferido que al postergado. Aparte de esto, cabe señalar que en ciertos casos solamente se da, de un lado, una inclinación favorable y, de otra, un rechazo. Éstos son los casos de más franca y fácil preferencia, encuadrada dentro de los dos extremos de la polaridad valorativa. En otros casos, lo que encontramos es una mayor inclinación que vence a una menor; por contraste, el objeto menos favorecido resulta rechazado, pero no en el sentido fuerte en que hay rechazo en la aversión o el odio. Por último, no siempre el placer o el agrado coincide con la preferencia, pues cabe preferir algo que produce menos agrado o placer que otra instancia.

4.42. Se hace entonces claro que, como señalamos, no es lo mismo el preferir que el conflicto de valoraciones, ni siquiera de afectos, pues cabe acceder a una preferencia sin grandes tensiones anímicas y sin que exista un momento de equivalencia en el favor y el disfavor del sujeto, que es lo que ocurre justamente en el conflicto. Puede decirse inclusive que el conflicto es contrario al preferir en la medida en que el balance del conocimiento y de Ia inclinación respecto a uno y otro objeto da por resultado, en el conflicto, una equivalencia. Para resolverlo hay que ir más allá de la preferencia como tal y acceder al dominio de la elección.

4.43. A propósito de lo último notemos que basta con que haya un conato de actividad para que la preferencia sea efectiva, o sea que el preferir y el postergar no requieren decisiones de la voluntad ni una conducta que se vuelque hacia el mundo exterior para modificarlo. De allí que puedan referirse a todo tipo de objetos de que se tiene conciencia. Dicho con otros términos, esto significa que el preferir y el postergar no suponen, como condición necesaria, ningún acto de realización de valores.

4.50. Estrechamente vinculada con la preferencia está la jerarquización, que es uno de los más característicos actos de la vida valorativa. Asignar rangos y establecer órdenes de prioridades, señalando lo que es superior y lo que es inferior, son funciones ordinarias de la conciencia valorativa, ge- 
neralmente reconocidas sin discusión como modos de comportarse diferentes a los de la conciencia constativa o neutral. Consideremos las relaciones principales de este género de vivencias y los caracteres de la jerarquización como tal a que dan nacimiento:

4.51. Jerarquizar consiste en asignar un rango, un orden de prioridades, comprendido entre lo superior y lo inferior, a varias instancias objetivas. Para que esto ocurra es preciso atribuir valor a dichas instancias y formular sobre ellas un juicio comparativo en una o varias vivencias de preferencia. Según esto, el preferir es la base del jerarquizar y lo precede. Cabría decir, por otra parte, que a menudo el preferir tiene como efecto una jerarquización de las instancias objetivas consideradas o tiende a ella.

4.52. Es necesario, sin embargo, llamar la atención sobre el hecho de que las preferencias no siempre se traducen en jerarquizaciones - cuando menos explícita y formalmente concebidas como tales-, lo cual es muy explicable si se acepta que en el jerarquizar hay un elemento de permanencia y de generalidad que contrasta con la posibilidad de preferencia pasajeras y circunscritas a instancias muy localizadas. Podría, pues, independizarse el preferir del jerarquizar, aunque no éste de aquél, y concebir la jerarquización como una función segunda de la apreciación comparativa de valores, que implica una cierta permanencia y generalidad. Por ejemplo, cuando yo prefiero un alimento a otro en un momento dado, me circunscribo a esos dos objetos y me atengo simplemente a su valor percibido en el momento. No diré entonces que estoy estableciendo propiamente una jerarquía de alimentos. Esto sólo ocurrirá propiamente cuando tome en cuenta dos o más grupos o clases de alimentos, apreciados en una serie en principio abierta de experiencias valorativas, como resultado de lo cual yo establezco un orden de superioridad alimenticia. Por cierto que entre una y otra clase de vivencias valorativas no se encuentran diferencias de esencia sino tan sólo de grado.

4.61. Hemos dicho que la preferencia se opone a la postergación; ambas sin embargo, como apreciaciones comparativas del valor se oponen a la indiferencia. Frente a la inclinación estimativa por un objeto antes que por otro, y frente a la desvalorización de un objeto frente a otro, la indiferencia es una vivencia de suspenso. Este suspenso puede ser de dos clases, o bien es un caso de desinterés respecto a las instancias consideradas, o bien es un caso de equivaloración, es decir, de apreciación igual de dos o más objetos. Este segundo caso es característicamente valorativo, mientras el primero puede ser una forma de la conciencia neutra. La equivaloración no debe ser confundida tampoco con el conflicto de valoraciones, aunque no sean raros los conflictos valorativos que son acompañados de equivaloraciones o se producen por ellas. 


\section{5.o. La elección valorativa}

5.11. La elección es una operación por la cual, de un conjunto de posibilidades reales de acción con respecto a una o más instancias objetivas, se realiza conscientemente una y se descartan las demás, sobre la base de vivencias de preferencia. Empleando una terminologia distinta, aunque coincidente en su sentido, puede decirse que elegir es dar paso a una realización de valor antes que a otra o realizar un valor en lugar de otro. Ejemplos de elección, en este sentido, son: el comprar un libro entre varios que se ofrecen en venta, el retirarse de una reunión en lugar de permanecer en ella, el votar por un candidato en un acto de sufragio, etc.

5.12. De lo anterior se colige que la elección es diferente de la preferen. cia y de la realización de valores, pero las supone. Es distinta de la primera porque la preferencia, como hemos visto en 4.43 , es completa como acto sin necesidad de ningún efecto exterior o modificación de la realidad y sin decisión voluntaria; basta que haya un conato de actividad para que exista preferir. En cambio, la elección requiere una decisión de la voluntad y una intervención (o abstención de intervenir) en la realidad. De allf que el campo objetivo al que se proyecta la elección sea más restringido que el de la preferencia: sólo se puede actuar sobre lo real que está al alcance de la voluntad, mientras que, como sabemos, se puede preferir cualquier clase de objetos.

5.13. Con respecto a la realización de valores, la diferencia, en primer lugar, toca también a la intervención de la voluntad, que ya sabemos no se da siempre ni necesariamente, aunque sea frecuente, en la realización. En segundo lugar, ésta es un acto referido en principio a una sola instancia, que no requiere la comparación, mientras que la comparación es indispensable en la elección pues supone un preferir.

5.21. La vinculación arriba señalada de la preferencia y la realización de valores con el elegir parece contradicha por ciertos casos muy comunes de elección. Por ejemplo, si en un experimento psicológico se le dice a un sujeto que escoja la figura más grande de un conjunto de figuras pintadas en un cuadro, él, al tomar una de ellas, parece ejecutar un acto de elección, aunque no se pueda decir que en este acto se halla necesariamente ni tam. poco ordinariamente implicada una preferencia en sentido estricto, ni una realización de valores. El elegir la figura más grande como tal puede cumplirse, en unos casos, estando el sujeto a favor de dicha figura, on otros, es. tando en contra $y$, en otros, siendo completamente indiferente al tamaño de las figuras. Puede, pues, realizarse teóricamente en ausencia de una actitud estimativa cualquiera y por tanto de la preferencia y la realización valorativa. Con lo cual no habría variado en nada la naturaleza del acto que el investigador de nuestro supuesto experimento le habría indicado hacer al su 
jeto al decirle que escoja la figura más grande. ${ }^{25}$ La situación es diferente cuando consideramos, por ejemplo, el fallo de un jurado en un concurso artístico, en que se trata de elegir una de las obras presentadas y otorgarle un premio. No cabe pensar que un miembro del jurado elija efectivamente un cuadro y que, al mismo tiempo esté en contra de él o sea indiferente con respecto a su valor intrínseco y a su valor relativo a los demás, sin que varíe la naturaleza del acto y pueda seguir diciéndose que ha elegido. Este caso exige una consideración especial que haremos en lo que sigue.

5.22. Una diferencia interesante, que resulta de lo que acabamos de decir, es que en el último caso puede hablarse (y suele hacerse así cuando se quiere establecer los contrastes necesarios) de una elección auténtica opuesta a una elección inauténtica. Si un miembro de jurado exige contra su preferencia hay inautenticidad en la elección, lo cual es una forma diferente de decir que la elección ha sido desnaturalizada. En cambio, en el primer caso, el sujeto puede tomar la figura $X$, estando contra ella o siendo indiferente desde el punto de vista estimativo, sin que tenga que decirse que hay inautenticidad en su acto.

De lo anterior se sigue que hay dos tipos diferentes de actos a los cuales suele llamarse elección. El primero consiste en discernir y separar, de un conjunto de objetos - las figuras presentadas por el experimentador- una, de acuerdo a determinada característica, v. gr., la más grande. El segundo comporta, además de estos elementos, una preferencia y una realización de valor, es decir, un juicio comparativo según el cual se afirma que uno de los objetos es mejor que los demás, y un acto por el cual se lo establece como el más valioso en la realidad. Este último acto es a veces simplemente una declaración verbal por la cual ocurre un cambio en la situación del objeto preferido; como vimos, ${ }^{26}$ se trata de una forma de la realización de los valores porque con ello la realidad queda de alguna manera determinada por la conciencia del valor. Por ejemplo, si un jurado elige ganador a un escritor en un concurso lo ha preferido y además ha determinado la realidad -por el premio, la fama que el escritor gana, etc.-, como consecuencia del juicio de valor.

De acuerdo a lo anterior, llamaremos elección propia a los actos del segundo tipo, esto es, a los que se ofrecen como forma de la vivencia valorativa, y elección impropia a los que son posibles con una mera conciencia neutra. ${ }^{27}$

25 Por cierto que puede decirse que cl sujeto normalmente está a favor de algo vinculado con la situación que vive, por ejemplo, a favor del experimento en que interviene, al que le reconoce valor y por eso participa en él. Pero es obvio que no es respecto a esto que se le pide elegir.

26 Cf. los parágrafos 3.13-3.14 sobre la realización verbal de valores.

27 Se entiende que aquí sólo nos interesan los actos de elección propia y a cllos nos referimos en lo que sigue al hablar de elección. 
5.31. En la elección, el sujeto atribuye valor paralelamente a varias instancias objetivas, prefiere una de ellas y la realiza. La elección implica así la realización de una posibilidad objetiva entre varias, sobre la base de una preferencia. Por tanto, posee todas las caracteristicas propias de la preferencia que hemos estudiado en los parágrafos anteriores. No hay elección propia sin un momento de acción exterior valorativamente orientado. Se dan por cierto aspectos o lapsos de la conducta electiva en que todavía no se produce propiamente una actuación sobre el mundo. Por ejemplo, el miembro del jurado -en el ejemplo anterior- se resuelve a dar el premio a uno de los concursantes, pero todavía no actúa en consecuencia; hay aquí ya algo de elección pero no consumada, un modo imperfecto, diríamos, del elegir. La elección no es cabal hasta que el sujeto no manifiesta su opinión, firma un acta, etc., es decir, realiza todos los actos derivados de la decisión que sean pertinentes $\mathrm{e}$ indispensables. La cadena entera de estos actos es lo que hay que considerar elección strictu sensu.

5.32. Otra condición indispensable para que haya elección es que los actos y los objetos a que se refiere la decisión sean por igual realizables. No cabe hablar de elección si una de las alternativas entre las que se elige es imposible o prácticamente inalcanzable por el sujeto. Por ejemplo, no cabe elegir entre ir al centro de la Tierra o ir a Europa, pues la primera alternativa es imposible. Es necesaria la igualdad de las instancias propuestas a la elección en este respecto, aunque sean admisibles otras diferencias tocantes inclusive a la mayor o menor posibilidad de realización de los objetos valorados y de los actos que se proyectan a ellos.

5.4. Un sujeto puede mentir con respecto a la atribución de valor y a la preferencia que hace suyas. No puede, en cambio, mentir con respecto a su elección, como no le es tampoco posible realizar falsamente un valor. Al tratar de la realización hemos visto las vivencias posibles a este respecto..28 Las mismas situaciones se repiten en el caso de la elección. En la medida en que es una acción sobre el mundo, y no meramente una representación $o$ un juicio, ella se produce o no se produce, y en cuanto se produce realiza una posibilidad $u$ otra, lo cual no puede ser nunca un engaño. Si el jurado dice que el escritor $X$ es el ganador, entonces ha sido elegido ganador y la elección se ha producido. La única alternativa es aquí, como en la realización, ${ }^{29}$ que la decisión y el acto externo no coincidan con la preferencia interiormente reconocida, lo cual no da una mentira sino una elección inauténtica. ${ }^{30}$

5.51. La polaridad estimativa se mantiene en la eỉección. No es posible elegir auténticamente, en el mismo tiempo y respecto, dos instancias, una

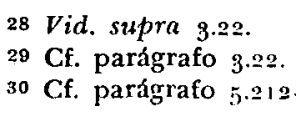


positiva y otra negativamente valoradas. Salvo que se introduzcan cambios en el objeto o en el concepto, o que se produzca una alteración de la situación que afecte a la valoración, no podrá considerarse elegido (o elegible) frente a $\mathrm{Y}, \mathrm{Z}$ y otros objetos concurrentes, a un objeto $\mathrm{X}$ que ha sido desechado. Si $\mathrm{X}$ es elegido, $\mathrm{Y}$ es desechado, si es alternativo, y, a la inversa, si $\mathrm{Y}$ es elegido, $\mathrm{X}$ será desechado. Salvo inautenticidad, en todos los casos el objeto elegido es el preferido y el objeto desechado es el postergado. Lo cual da una versión ampliada del principio de la oposición polar de las valoraciones.

5.52. Nuestra última observación y, con ella, en parte, el principio de la oposición que hemos extendido a la elección, parecen desmentidos por ciertos casos en que se diría que lo preferido y lo elegido no coinciden. Podría alegarse, en efecto, que un sujeto puede, por ejemplo, preferir -es decir, considerar comparativamente mejor a una mujer y elegir como esposa a otra, comparativamente inferior, debido a que la primera está lejos de sus posibilidades y la segunda no. Habría entonces una elección contraria a la preferencia. Sin embargo, mirado más de cerca, este ejemplo se deja interpretar, bien como un caso de aparente alternativa, pues uno de los términos es imposible, lo cual como sabemos anula la elección, bien como un caso de preferencia múltiple en el cual una de las apreciaciones comparativas se refiere, $v$. $g r$. , a la belleza, otra a la clase social, otra a la posibilidad de tener aceptación, otra a la accesibilidad, traduciéndose en la elección la preferen. cia dominante.

5.6. La elección es una conducta muy importante en relación con el conflicto de valoraciones. Ya hemos visto al tratar de la atribución de valor que algunas veces las calificaciones paralelas colisionan unas con otras. ${ }^{31}$ EI sujeto está entonces en suspenso, pues se ha comprometido con la afirmación de un contenido valioso y con su opuesto. Por ejemplo, un sujeto puede llegar a reconocer que ha dado su palabra de no revelar un secreto $y$, por otra parte, ha prometido revelarle a una persona o a una institución toda la in. formación que posea. Ha aceptado, pues, la bondad de un acto y la de su contrario. Vive, en consecuencia, un conflicto de valoraciones. Pues bien, cuando este conflicto no se resuelve por cambio de la situación (como sería el caso de la liberación de la promesa, de la muerte de la persona a quien se prometió revelar toda la información, etc.), exige una elección que rompa la equivalencia de las valoraciones. Según esto, hay casos en que la elección no opera sobre la base de una preferencia y de la correspondiente postergación, sino de dos preferencias contradictorias, que se anulan mutuamente. En esta coyuntura, la elección revela su esencia volitiva. En verdad sólo por la voluntad es posible, aunque la preferencia la alimente y la motive en gran número de casos.

31 Parágrafo 2.8 . 


\section{6.oo. Los dos niveles de la vida valorativa}

6.ol. Hasta aquí hemos descrito y analizado la valoración tomándola como una experiencia que se desenvuelve en un solo nivel y que, en este sentido, es esencialmente unitaria, a despecho de la multiplicidad de sus formas. Tal proceder era aconsejable para fijar los tipos principales de comportamiento estimativo (como, $v$. gr., la atribución y la realización de valor, la preferencia o la postergación y la elección) y para precisar suficientemente sus diferencias relativas más generales. Una vez cumplido este cometido, conviene atender a las diferencias de nivel que, como hemos de ver, provocan una a manera de dualidad de la vida valorativa cuya comprensión adecuada exige diversificar y matizar los enfoques. ${ }^{32}$

Los parágrafos siguientes estarán dedicados a presentar y analizar los dos niveles en que, a nuestro entender, se desenvuelve la vida valorativa. A lo largo de ellos haremos mención unitaria de la atribución de valor y las otras clases de vivencia estimativa ya estudiadas, deteniéndonos sólo a considerar los casos y aspectos en que las diferencias de nivel determinen distinciones entre tales vivencias que convenga poner de resalto.

6.11. Recordemos algunas afirmaciones hechas anteriormente al tratar de la forma básica de la valoración que es el acto de atribución de valor. Señalamos que el sujeto califica a una instancia objetiva y que esta calificación suele hacerse sobre la base de un concepto de la cosa buena (en el género correspondiente), vinculada con un patrón y con criterios de valoración. Esta manera de valorar es por cierto muy común y normal, pero no es la única. Una via de orientación hacia otras formas de valoración la ofrece el inquirir por el origen del patrón de valoración. En la misma dirección nos proyecta la comprobación de casos en que dos o más personas difieren no sobre el valor sino sobre el patrón de valoración que hay que aplicar para apreciar un objeto. Lo que entonces se advierte con suficiente claridad es que, al lado de las valoraciones que emplean un patrón establecido y reconocido, hay experiencias en que no se opera con un patrón constituido.

6.12. Con ello se pone de resalto la existencia de los dos niveles de valoración a que hemos aludido, a saber, el de aquellas experiencias estimativas que siguen una pauta ya establecida, derivada de experiencias anteriores, que vamos a llamar valoraciones derivadas o segundas, y el de aquellas que llamaremos valoraciones originarias, primitivas o protovaloraciones, caracterizadas por ia ausencia de un patrón preexistente, las cuales suponen una decisiva participación de la espontaneidad del sujeto.

6.13. Como la gran mayoría de las distinciones reales, ésta es sólo de

32 Esta diferenciación resulta de primera importancia en el tratamiento de la problemática de la fundamentación del valor. Sin embargo, como hemos dicho, aquí no la abordaremos. 
grado, no de esencia. No cabe hablar en términos absolutos de una vivencia originaria y de una vivencia derivada, aunque sólo sea a causa de la esencial historicidad del hombre. De allí que sea posible encontrar casos de vivencias que resultan mejor descritas diciendo que pertenecen a un nivel intermedio entre los dos señalados, el nivel de las valoraciones que podemos llamar criticas, ${ }^{33}$ que ofrecen bien marcados rasgos de derivación, como es básicamente el trabajar con un patrón previo y, a la vez, de originalidad, como es la remodelación de dicho patrón.

6.14. Las varias formas de experiencia estimativa que hemos estudiado, y otras que dejamos de considerar por mor de la brevedad, se dan en los niveles señalados. Hay, en efecto, una atribución de valor como valoración originaria y como valoración derivada; hay una realización de valor que obedece a patrones fijos, otra que los acepta parcialmente y otra que prolonga la protovaloración; hay preferencias y postergaciones, así como elecciones que se atienen a criterios más o menos codificados y, de otro lado, juicios comparativos y opciones que traducen un fiat originario del sujeto.

6.21. Distinguimos tres clases principales de valoraciones derivadas, a saber, las que llamaremos valoraciones aprendidas, transferidas e imitadas. Es común a todas ellas el operar con un concepto ya constituido de la cosa buena (en su género), y el empleo, para formular el juicio correspondiente, de patrones y criterios establecidos. Sobre este fondo común, las valoraciones aprendidas se singularizan por comportar la aceptación consciente y deliberada de un patrón valorativo que otra u otras personas proponen y emplean y en aceptarlo con plena convicción sobre su vigencia. Se hace claro con esto que pueden existir y de hecho existen muy normalmente una instrucción y un aprendizaje en materia estimativa, los cuales comportan las notas de conciencia, voluntad y convicción. Se dice que alguien ha aprendido a va. lorar un género de objetos, $v$. gr., autos, cuando conoce el correspondiente patrón valorativo por acción directa o indirecta de otro sujeto, no opone reparos a esta acción, hace suyo el concepto de cosa buena implicado en el patrón y como resultado puede usar los criterios que deciden cuándo una cosa del género es valiosa.

Seguramente puede decirse sin riesgo de error que ésta es la más común y típica conducta de aprendizaje valorativo. Porque, de otra parte, en el nivel de las protovaloraciones difícilmente puede hablarse de un aprendizaje estimativo. Esto no es de extrañar, si se tiene en cuenta que las valoraciones aprendidas conforman el fondo constante de las atribuciones ordinarias de valor y de las otras formas de la estimación. Por su parte, la valoración crítica es sólo parcialmente aprendida, como corresponde a su carácter intermedio o mixto.

33 A este concepto debe referirse el de la crítica valorativa en sus varias formas (lite raria, moral, etc.), con sus vivencias características. 
6.22. Las valoraciones trasferidas presentan una diferencia importante con respecto a lo anterior. En ellas falta la conciencia de que los patrones adquiridos y aplicados proceden de otros hombres. El sujeto los acepta y los emplea con plena convicción, pero no advierte propiamente que le vienen de los demás. Aunque también podría hablarse aquí de aprendizaje en sentido lato, preferimos denominar transferencia a esta forma de adquisición de conceptos valorativos porque cubre una amplia gama de acciones y efectos no conscientes. Por ejemplo, un niño que vive en un medio en que predomina la segregación racial (aun en los casos en que ésta no es oficialménte aceptada), adquirirá el hábito de calificar negativamente a los miembros del grupo racial segregado. A no dudar, éste es generalmente un proceso que se cumple fuera del control de la conciencia y que no conviene llamar aprendido en sentido estricto.

6.23. La tercera de estas valoraciones es la imitada. En ella no falta la conciencia sino más bien, en mayor o menor medida, la convicción plena. El sujeto valora al modo usual, siguiendo la pauta de la conducta de otros, pero no lo hace con la convicción cabal que da carácter personal y resonancia interior a los juicios valorativos. Un snob, por ejemplo, adopta los patrones ajenos sin participar emocionalmente en los juicios que expresa y acepta. Hay también por cierto en este caso un compromiso del sujeto, pero es, por decirlo asi, un compromiso frio, exterior. De alli el nombre de valoración imitada (o remedada) que damos a esta clase de experiencia.

6.31. Lo característico de las valoraciones originarias o protovaloraciones es, como sabemos, que el sujeto procede a atribuir valor (o a realizar, preferir o elegir) sin apoyarse en un patrón previamente establecido, es decir, en plan directo o espontáneo. El ejemplo mejor de esta vivencia es el ofrecido por las grandes revoluciones artísticas o morales, en las cuales emerge una nueva idea de lo bueno estético o práctico. Para hablar de protovaloraciones no es necesario, sin embargo, referirse a coyunturas excepcionales de la vida humana histórica. Cualquier persona o grupo humano, en las circunstancias más diversas de la existencia, llega a funcionar, aunque no frecuentemente, como un inventor de valores, esto es, como un sujeto que vive en el nivel de las experiencias estimativas originarias.

6.32. Cabe señalar dos clases principales de protovaloraciones, a saber: las que vamos a llamar libres, y las que designaremos con el nombre de formulaciones de patrones. Esta distinción es sólo analíticamente válida, pues puede decirse que, en rigor, toda protovaloración comporta un elemento esencial de libertad (por lo menos con respecto a los patrones establecidos), sin lo cual no sería propiamente originaria, y que, inversamente, hay siempre en la vivencia originaria una formulación de patrones cuando menos implícita. Sin embargo, la distinción es conveniente porque permite subrayar, en un caso, un momento de evaluación (que puede ser fugaz, sin per- 
juicio de su efectividad) y una cierta independencia de la vivencia con respecto a las consecuencias que se deriven de ella, especialmente en el plano social, y, en el otro, la intención consciente de establecer una norma de valoración nueva y a la vez más o menos estable y comunicable. Compárese, por ejemplo, la manera como vive su acto valorativo un hombre que, habitualmente sumiso y conformista, se rebela un día y rechaza determinadas formas codificadas de conducta, si bien luego vuelve a su comportamiento ordinario, y la manera como lo vive un reformador moral o político que descalifica sistemáticamente la conducta social y propone nuevas pautas de conducta. Obviamente la diferencia no reside en la prescindencia de pautas y reglas de valoración pre-establecidas sino en la espontaneidad y el eventual inmediatismo del primer tipo de actos y en el carácter deliberado : sistemático del segundo. Cuando del primero se derivan patrones de calificación, es sólito que sea por la intervención de terceras personas (los discípulos, los seguidores, los imitadores, etc.), que dan carácter fijo y compartible a lo que pudo ser vivido como fugaz y privado; en cambio, lo típico de los segundos es que las normas surjan justamente por acción del propio sujeto que tuvo originalmente la vivencia valorativa.

6.33. La ausencia de patrones estimativos previos en las protovaloraciones da a la voluntad un papel preponderante. Como en ellas se trata de decidir la calificación que conviene a un género de objetos (en términos absolutos o relativos), resulta indispensable un elemento volitivo de decisión última. Se establece así una nueva diferencia entre las dos clases extremas de valoraciones que hemos precisado: no se concibe una protovaloración sin decisión voluntaria, pero sí una valoración derivada.

6.34. Aunque en la protovaloración no puede faltar la conciencia de los carcateres objetivos de las cosas valoradas, no desempeña el papel principalísimo que tiene en las valoraciones derivadas, justamente porque el uso de un patrón valorativo, que falta en el primer caso, implica como sabemos una correlación fáctico-axiológica previa, a la que tiene que ceñirse el sujeto. Importa señalar, de otro lado, que al no echarse mano de un patrón en las protovaloraciones, cambia la función de las notas objetivas de lo valorado. Operan no como criterios de calificación sino como puntos de partida o estímulos de la decisión voluntaria, de la que surgirán nuevos patrones.

6.35. Por último, si bien algunas axiologias defienden la tesis de que en la valoración obra una suerte especial de intuición capaz de dar el valor directa y plenamente y como una instancia a priori, descriptivamente no puede registrarse una vivencia de tal tipo. ${ }^{34}$ En cambio, sí cabe poner énfasis en la importancia que en este sentido adquieren ordinariamente las vivencias

34 Quede bien en claro que no estamos discutiendo la validez del intuicionismo ni proponiendo otra teoría interpretativa; queremos limitarnos, hasta donde sea posible, a los datos descriptivos. 
de tipo hedónico-afectivo. Sin funcionar necesariamente como razones o fundamentos de una valoración, suelen motivarla e impulsar las decisiones del sujeto en gran número de casos.

6.40. Las valoraciones de nivel intermedio, o sea, las que hemos denominado criticas, se caracterizan por la convergencia de elementos de decisión originaria e innovación, y elementos de hábito o uso convencional de patrones. Caben por cierto aqui, como se comprende de suyo, todas las variaciones y matices, pues se trata de fenómenos de transición y no de especies absolutas. Sin embargo, pueden distinguirse las siguientes clases suficientemente marcadas: la aclaración, la modificación y la composición de patrones, y la adaptación de éstos a usos nuevos. Consideremos, aunque sea brevemen. te, estos casos.

6.41. En la aclaración el sujeto dispone de un patrón valorativo y su actitud es de aceptación normal de él. No obstante, dicho patrón no se ofrece de modo preciso y bien determinado, dando pábulo a confusiones y errores de aplicación. Se requiere entonces un acto por el cual se definan sus elementos constitutivos. Piénsese, por ejemplo, en el caso de una ley y en la necesidad en que frecuentemente se encuentran los jueces de interpretarla. Tal interpretación, en sus aspectos estimativos, corresponde a una vivencia de aclaración valorativa.

6.42. En la modificación de patrones el sujeto opera sobre un modelo básico eliminando, sustituyendo o complementando sus elementos. Cuando, en cambio, se parte explícitamente de dos o más patrones y de ellos se trata de obtener uno nuevo, que reúna los elementos de los anteriores y, en cierto modo, los sustituya, tenemos un caso de composición. Ejemplos de estos actos son las transformaciones y refundiciones de estilos y motivos literarios cuando implican un momento básico de originalidad y no se reducen a meras vivencias imitativas.

6.43. La alteración debe considerarse como un caso aparte, pues difiere de las vivencias arriba descritas en que comporta un momento de inadvertencia o ignorancia, o una decisión de engañar a terceras personas con respecto al patrón. Hay, pues, alteración cuando el patrón valorativo pertinente se cambia y viene a ser tomado por otro, en virtud de la intervención del sujeto. Piénsese, $v$. gr.; en los modelos sociales propuestos por los demagogos y se tendrá un caso típico de alteración de patrones.

6.44. Hay, finalmente, adaptación cuando, sin que en lo esencial se introduzcan cambios en el patrón, el sujeto opera con él de modo original, aplicándolo a situaciones nuevas o dándole un uso que primitivamente no tuvo. El traslado de modelos del cine al teatro o de la novela al cine son muestras típicas de esta conducta valorativa.

Augusto Salazar Bondy

Universidad Nacional de San Marcos, Lima 